\title{
Treatment strategies for women with WHO group II anovulation: systematic review and network meta-analysis
}

\author{
Rui Wang, ${ }^{1,2}$ Bobae V Kim, ${ }^{1}$ Madelon van Wely, ${ }^{3}$ Neil P Johnson, ${ }^{1,4}$ Michael F Costello, ${ }^{5}$ \\ Hanwang Zhang, ${ }^{2}$ Ernest Hung Yu Ng, ${ }^{6}$ Richard S Legro, ${ }^{7}$ Siladitya Bhattacharya, ${ }^{8}$ \\ Robert J Norman, ${ }^{1,9,10}$ Ben Willem J Mol, ${ }^{1,11}$
}

For numbered affiliations see end of the article

Correspondence to: R Wang, University of Adelaide, North Adelaide, Australia,

r.wang@adelaide.edu.au

Cite this as: BMJ 2017;356:ej138 http://dx.doi.org/10.1136/bmj.j138

Accepted: 29 December 2016

\section{ABSTRACT}

OBJECTIVE

To compare the effectiveness of alternative first line treatment options for women with WHO group II anovulation wishing to conceive.

DESIGN

Systematic review and network meta-analysis.

DATA SOURCES

Cochrane Central Register of Controlled Trials, Medline, and Embase, up to 11 April 2016.

\section{STUDY SELECTION}

Randomised controlled trials comparing eight ovulation induction treatments in women with WHO group II anovulation: clomiphene, letrozole, metformin, clomiphene and metformin combined, tamoxifen, gonadotropins, laparoscopic ovarian drilling, and placebo or no treatment. Study quality was measured on the basis of the methodology and categories described in the Cochrane Collaboration Handbook. Pregnancy, defined preferably as clinical pregnancy, was the primary outcome; live birth, ovulation, miscarriage, and multiple pregnancy were secondary outcomes.

\section{RESULTS}

Of 2631 titles and abstracts initially identified, 54 trials reporting on 7173 women were included. All pharmacological treatments were superior to placebo or no intervention in terms of pregnancy and ovulation. Compared with clomiphene alone, both letrozole and the combination of clomiphene and metformin showed higher pregnancy rates (odds ratio $1.69,95 \%$ confidence interval 1.33 to $2.14 ; 1.71$, 1.28 to 2.27 ; respectively). Letrozole led to higher live

\section{WHAT IS ALREADY KNOWN ON THIS TOPIC}

Clomiphene is the longstanding first line treatment for WHO group II anovulation

Existing pairwise meta-analyses are limited to comparisons of two treatments

\section{WHAT THIS STUDY ADDS}

This study compares all of the most common regimens of ovulation induction with each other, using direct and indirect means

All pharmacological ovulation inductions were superior to placebo or no treatment in terms of ovulation and pregnancy in women with WHO group II anovulation

Letrozole was the most effective treatment in terms of live birth, and one of the top three treatments in terms of pregnancy and ovulation

Clomiphene and metformin combined was the most effective treatment in terms of pregnancy but not live birth; the potential higher chances of side effects should also be taken into account in decision making

Metformin and letrozole were associated with the lowest rates of multiple pregnancy birth rates when compared with clomiphene alone $(1.67,1.11$ to 2.49$)$. Metformin led to lower multiple pregnancy rates compared with clomiphene alone (0.22, 0.05 to 0.93$)$.

\section{CONCLUSIONS}

In women with WHO group II anovulation, letrozole and the combination of clomiphene and metformin are superior to clomiphene alone in terms of pregnancy. Compared with clomiphene alone, letrozole is the only treatment showing a significantly higher rate of live birth.

\section{SYSTEMATIC REVIEW REGISTRATION PROSPERO CRD42015027579.}

\section{READERS' NOTE}

This is the second version of this paper. The original version was corrected following the retraction of two studies and removal of another which were ineligible (references 40, 41, and 75 of the original paper). These studies are not shown in this version. A tracked changes version of the original version is attached as a supplementary file to the correction notice, which explains the issue further.

\section{Introduction}

Infertility affects one in seven couples, and ovulation disorders account for a quarter of all cases. ${ }^{1}$ Normogonadotrophic anovulation, also classified as World Health Organization group II anovulation, is the most common category of anovulatory infertility. Within this group, polycystic ovary syndrome (PCOS) is by far the most prevalent cause. ${ }^{2}$

PCOS was first described in 1935 by Stein and Leventhal. ${ }^{3}$ Previously described in several different ways, the diagnostic criteria for PCOS, agreed jointly by the European Society of Human Reproduction and Embryology and the American Society for Reproductive Medicine, are known as the Rotterdam criteria. ${ }^{4} 5$ These criteria are also endorsed by the Endocrine Society ${ }^{6}$ and are used by a wide range of medical professionals, and not just obstetricians and gynaecologists. The clinical manifestations of PCOS include oligomenorrhoea or amenorrhoea, hirsutism, and frequently infertility. ${ }^{7}$ From conception, women with PCOS and their infants are at increased risk of perinatal complications, including gestational diabetes, pre-eclampsia, preterm labour, and neonatal morbidity. ${ }^{8-10}$

Safe and effective ovulation induction is important for women with WHO group II anovulation who wish to conceive, to avoid premature exposure to in vitro fertilisation, which is invasive, expensive, and associated with potentially higher chances 
of perinatal complications and congenital abnormalities. ${ }^{11-14}$ Several medical options are used to treat ovulation disorders and infertility, including oestrogen receptor modulators (such as clomiphene and tamoxifen), aromatase inhibitors (such as letrozole), insulin sensitising drugs (such as metformin), and direct hormonal stimulation of the ovaries (gonadotropins), with laparoscopic ovarian drilling being a surgical alternative.

Traditional pairwise meta-analysis only allows the comparison of two interventions for ovulation induction. ${ }^{15-20}$ However, many of these treatment strategies have not been compared directly in previous randomised controlled trials. Therefore, it is difficult to identify the most effective treatment based on direct evidence. Network meta-analysis, also known as multiple treatment comparison meta-analysis, compares multiple treatments in one statistical model, ${ }^{21-23}$ and provides a hierarchy of effectiveness of these treatments that can guide decision making. ${ }^{24} 25$ The application of network meta-analysis is crucial in areas where multiple interventions are available, such as in WHO group II anovulation.

We therefore performed a systematic review and network meta-analysis to compare the effectiveness of different treatment options, including clomiphene, letrozole, metformin, clomiphene and metformin combined, tamoxifen, gonadotropins, laparoscopic ovarian drilling, and placebo or no treatment, in women with WHO group II anovulation, and to identify the best strategy for first line treatment.

\section{Readers' note}

This is the second version of this paper. The original version was corrected following the retraction of two studies and removal of another which were ineligible (references 40, 41, and 75 of the original paper). These studies are not shown in this version. A tracked changes version of the original version is attached as a supplementary file to the correction notice, which explains the issue further.

\section{Methods}

\section{Search strategy and selection criteria}

We conducted and reported the study according to the preferred reporting items for systematic reviews and meta-analyses (PRISMA) extension statement for network meta-analyses. ${ }^{26}$ We performed an extensive electronic search of the Cochrane Central Register of Controlled Trials (CENTRAL), Medline, and Embase for randomised controlled trials. The search strategies were based on combinations of ovulation induction and anovulation (or PCOS), using both free words and index terms (appendix 1). We sought further trial details or protocols to establish eligibility of potential trials. We also searched previous published Cochrane systematic reviews on ovulation induction for additional studies. No language restrictions were applied. Our latest search was completed on 11 April 2016.

We included published and unpublished randomised controlled trials comparing one or more common ovulation induction options with placebo, no treatment, or other treatments: clomiphene, tamoxifen, letrozole, metformin, gonadotropins, laparoscopic ovarian drilling, or the combination of clomiphene and metformin. Treatments were categorised according to the initial randomised allocation, although subsequent clinical management might have included further doses or an alternative treatment.

Studies were excluded if they were not randomised controlled trials; only included treatment resistant women; or failed to report on clinical pregnancy, live birth, or pregnancy. Participants in the included studies were classified as: treatment naive women, a combination of treatment naive and treatment exposed women, and women whose treatment status was unknown. Crossover trials were also included if pre-crossover data were available. We also excluded those studies that only compared different doses of the same treatment option or compared the effects of adding medical adjuncts such as dexamethasone. Authors were contacted for further information if necessary.

\section{Patient involvement}

There was no patient involvement in framing the research question, choosing the outcome measures, or conducting the research. We plan to involve Fertility Network UK, PCOS Challenge, RESOLVE, and Access Australia's National Infertility Network in the dissemination of the research results by means of short, easy to read summaries of key results, infographics, and audio or video interviews that can be used by patients and caregivers.

\section{Data extraction and assessment of risk of bias}

Two reviewers (RW and BVK) independently assessed the eligibility of all identified citations, and extracted data from original trial reports using a specifically designed form that captured information on study design, trial setting, patient characteristics (inclusion criteria, age, body mass index, duration of infertility, history of ovulation induction), sample sizes, details of ovulation induction options, and outcomes. Disagreements were referred to a third reviewer (BWJM) to reach consensus.

We chose pregnancy, defined preferably as clinical pregnancy, as the primary outcome. Clinical pregnancy was defined as pregnancy diagnosed by ultrasonographic visualisation of one or more gestational sacs. ${ }^{27} 28$ Comparing the effectiveness of a treatment based on either clinical pregnancy or live birth rate as endpoints often results in comparable conclusions. ${ }^{29}$ Therefore, we used data on live birth or pregnancy (positive blood or urine test for human chorionic gonadotropin) as an outcome when data on clinical pregnancy were not available. Secondary outcomes were live birth, ovulation, miscarriage, and multiple pregnancy.

Study quality was assigned by two reviewers (RW and BVK) using the methodology and categories described in the Cochrane Collaboration Handbook. ${ }^{30}$ Again, in case of disagreement, a third reviewer (BWJM) was asked to reach consensus. Briefly, the tool for assessing 
risk of bias addresses seven specific domains: random sequence generation, allocation concealment, blinding of participants and personnel, blinding of outcome assessment, incomplete outcome data, selective reporting, and other sources of bias. Each domain is assigned a judgment relating to the risk of bias for that study classified as low risk, high risk, or unclear. We presented risk of bias graphs by Review Manager 5.3 software. ${ }^{30}$

\section{Data synthesis and statistical analysis}

A network meta-analysis was conducted to simultaneously compare seven treatment options for ovulation induction and placebo or no treatment for each outcome. In its simplest form, a network meta-analysis is the combination of direct and indirect estimates of relative treatment effect in one analysis. An indirect estimate of the relative treatment effect A versus B can be formed by comparing direct trials of $A$ versus $C$ with trials of $\mathrm{B}$ versus $\mathrm{C}$. Network plots were constructed to illustrate the geometry of the network. ${ }^{31}$

All network meta-analyses were conducted within a random effects multiple regression model using the mvmeta package in Stata software ${ }^{31} 32$ (version 12.0, Stata Corp). Where direct data were available, pairwise meta-analyses in random effects model were also performed in Stata and the agreement of direct and indirect evidence was assessed by an inconsistency plot. Studies with $0 \%$ or $100 \%$ events in all interventions were excluded from the analysis because these studies do not allow conclusions on relative effects. For studies with zero events in one arm only, we added a continuity correction of 0.5 to each cell. To avoid double counting of events, multi-intervention trials were analysed in their original form without the need to combine interventions.

For the network meta-analysis, we presented summary treatment effects (odds ratios) with their $95 \%$ confidence intervals as well as predictive intervals to facilitate interpretation of the results in the light of the magnitude of heterogeneity. ${ }^{31}$ Predictive intervals can provide an interval within which the estimate of a future study is expected to be. ${ }^{31}$ We applied the comparison adjusted funnel plot to assess small study effects in the network. We used the surface under the cumulative ranking curve to rank the treatments. ${ }^{3133}$ It is a percentage of the effectiveness of every treatment relative to an imaginary treatment that is always the best without uncertainty. We then performed sensitivity analysis to explore important network inconsistency. We restricted the analysis to those trials on treatment naive women, trials with low risk of randomisation and allocation bias, and trials reporting clinical pregnancy for sensitivity analysis.

\section{Results}

Characteristics of included studies

The literature search yielded 2631 publications, as shown in the PRISMA flowchart (fig 1). Fifty three ${ }^{34-89}$ publications reporting on 54 trials fulfilled the eligibility criteria, as one study ${ }^{56}$ included two individual trials (appendices 2 and 3).Five studies ${ }^{35} 36475267$ were crossover studies and eight studies 3544546166778687 were reported in conference abstracts. Publication dates ranged from 1966 to 2015, with 42 trials published in the last 10 years. The studies were conducted in various countries, and one study each was reported in French, ${ }^{46}$ Italian, ${ }^{80}$ Turkish, ${ }^{39}$ and Persian. ${ }^{69}$ The list of excluded studies is presented in appendix 4.

Of 54 trials, seven ${ }^{54} 565860648288$ had three comparison interventions and each of the remaining 47 trials had two. Overall, 7173 women with WHO group II anovulation were randomised to seven different treatment options (including clomiphene, letrozole, metformin, clomiphene and metformin combined, tamoxifen, gonadotropins, and laparoscopic ovarian drilling) and to placebo or no treatment. Appendix 5 presents the network plots for pregnancy, live birth, ovulation, miscarriage, and multiple pregnancy.

\section{Risk of bias assessment results}

There were 29 (54\%) randomised controlled trials with low risk of bias on random sequence generation and $25(46 \%)$ randomised controlled trials with low risk of bias on allocation concealment. Only 12 (22\%) trials had low risk of bias on both blinding of participants and outcome assessment. Appendix 6 shows results from the risk of bias assessment.

\section{Network meta-analysis results \\ Primary outcome-pregnancy}

Our network meta-analysis included 54 randomised controlled trials reporting on 7173 women. Of these trials, 18 evaluated a combination of clomiphene and metformin (981 women). The remaining trials offered one treatment in each intervention, including clomiphene (49 trials;

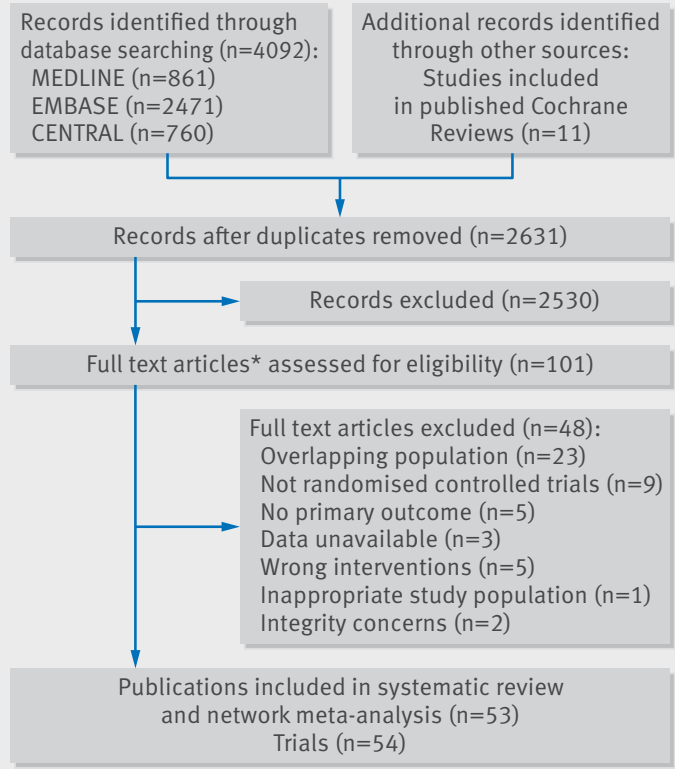

Fig 1 | PRISMA flow diagram of literature search for randomised controlled trials comparing eight ovulation induction treatments in women with WHO group II anovulation. *Full text articles=including abstract only publications 


\section{Comparison}

Clomiphene citrate versus

Placebo/no treatment

Letrozole

Metformin

Clomiphene citrate + metformin

Tamoxifen

Follicle stimulating hormone

Laparoscopic ovarian drilling

Placebo/no treatment versus

Letrozole

Metformin

Clomiphene citrate + metformin

Tamoxifen

Follicle stimulating hormone

Laparoscopic ovarian drilling

Letrozole versus

Metformin

Clomiphene citrate + metformin

Tamoxifen

Follicle stimulating hormone

Laparoscopic ovarian drilling

Metformin versus

Clomiphene citrate + metformin

Tamoxifen

Follicle stimulating hormone

Laparoscopic ovarian drilling

Clomiphene citrate + metformin versus

Tamoxifen

Follicle stimulating hormone

Laparoscopic ovarian drilling

Tamoxifen versus

Follicle stimulating hormone

Laparoscopic ovarian drilling

Follicle stimulating hormone versus

Laparoscopic ovarian drilling

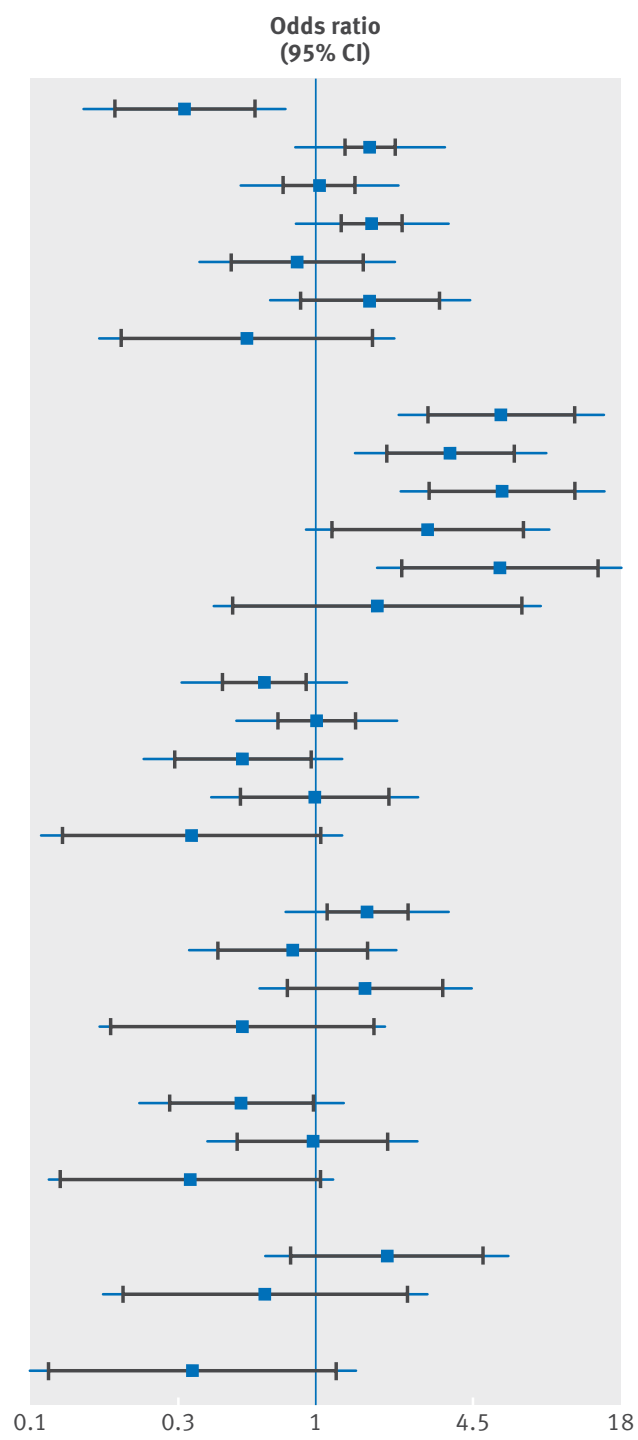

\section{Odds ratio \\ $(95 \% \mathrm{Cl})$}

0.29 (0.15 to 0.56$)$

1.69 (1.33 to 2.14)

1.04 (0.74 to 1.46$)$

1.71 (1.28 to 2.27 )

0.84 (0.45 to 1.58$)$

1.68 (0.87 to 3.24$)$

0.52 (0.16 to 1.74$)$

5.81 (2.90 to 11.67$)$

3.59 (1.97 to 6.56$)$

5.88 (2.95 to 11.72$)$

2.91 (1.17 to 7.23$)$

5.78 (2.28 to 14.66$)$

$1.81(0.46$ to 7.10$)$

0.62 (0.41 to 0.92$)$

1.01 (0.70 to 1.46$)$

0.50 (0.26 to 0.96$)$

0.99 (0.49 to 2.00$)$

0.31 (0.09 to 1.05 )

1.64 (1.12 to 2.40$)$

0.81 (0.40 to 1.65 )

1.61 (0.77 to 3.36)

$0.50(0.14$ to 1.75$)$

$0.49(0.25$ to 0.98$)$

0.98 (0.48 to 2.01)

0.31 (0.09 to 1.05 )

$1.98(0.80$ to 4.92$)$

0.62 (0.16 to 2.40 )

$0.31(0.08$ to 1.23$)$
(0.07 to 1.48$)$

(95\% Prl)

(0.11 to 0.75$)$

(0.83 to 3.43 )

(0.49 to 2.21)

(0.82 to 3.53)

(0.33 to 2.13)

(0.65 to 4.33)

(0.13 to 2.13)

(2.19 to 15.46$)$

(1.45 to 8.92)

(2.22 to 15.56)

(0.92 to 9.18)

(1.80 to 18.55$)$

(0.38 to 8.58 )

(0.28 to 1.35$)$

(0.47 to 2.17)

(0.20 to 1.28 )

(0.37 to 2.65)

(0.07 to 1.29)

(0.76 to 3.55$)$

(0.30 to 2.18)

(0.59 to 4.41)

(0.12 to 2.13$)$

(0.19 to 1.31$)$

(0.36 to 2.65)

(0.07 to 1.29$)$

0.63 to 6.25$)$

(0.13 to 2.90)

Fig 2 | Network meta-analysis of effectiveness of treatment options for pregnancy in women with WHO group II anovulation. Blue squares=estimate summary odds ratios of each comparison; black horizontal lines=confidence intervals; blue horizontal lines (overall length of lines)=predictive intervals (Prl); blue vertical line=line of no effect (odds ratio=1). Odds ratios less than 1 favour the first intervention; odds ratios greater than 1 favour the second intervention

3054 women), letrozole (20; 1540), metformin alone (14; 910), tamoxifen (three; 143), follicle stimulating hormone (two; 197), laparoscopic ovarian drilling (one; 36), and placebo or no treatment (eight; 312).

Figure 2 and table 1 show the network meta-analysis results. Compared with placebo or no intervention, all the treatment options (except for laparoscopic ovarian drilling) resulted in a significantly higher chance of pregnancy. Compared with clomiphene alone, letrozole as well as the combination of clomiphene and metformin led to significantly higher pregnancy rates (odds ratio 1.69 , $95 \%$ confidence interval 1.33 to $2.14 ; 1.71,1.28$ to 2.27 ; respectively). Similar differences could be found when we compared these two interventions with tamoxifen. The combination of clomiphene and metformin also led to a significantly higher pregnancy when compared with metformin alone $(1.64,1.12$ to 2.40$)$.

When we considered predictive intervals in a network meta-analysis, clomiphene, letrozole, metformin, follicle stimulating hormone, and clomiphene and metformin combined still led to higher pregnancy rates compared with placebo or no intervention. For those interventions compared directly, the results from pairwise meta-analysis and network meta-analysis were consistent, apart from follicle stimulating hormone versus clomiphene (table 1 and appendix 7).

The surface under the cumulative ranking curve was used to provide a hierarchical ranking of the different treatments. The efficacy of every intervention, expressed as a percentage, was considered in relation to an imaginary intervention assumed to be the best. Higher surface under the cumulative ranking curve values therefore correspond to more effective treatments. ${ }^{31}$ The surface under the cumulative ranking curve values for the eight ovulation induction regimens were $85 \%, 82 \%$, $84 \%, 47 \%, 43 \%, 35 \%, 20 \%$, and 3\%, for clomiphene and metformin combined, follicle stimulating hormone, letrozole, metformin, clomiphene, tamoxifen, 


\begin{tabular}{|c|c|c|c|c|}
\hline \multirow[b]{2}{*}{ Treatment comparison* } & \multicolumn{2}{|c|}{ Pairwise meta-analysis } & \multicolumn{2}{|c|}{ Network meta-analysis } \\
\hline & No of studies & Odds ratio $(95 \% \mathrm{Cl})$ & Odds ratio $(95 \% \mathrm{Cl})$ & $95 \% \mathrm{Prl}$ \\
\hline \multicolumn{5}{|l|}{ Clomiphene citrate versus: } \\
\hline Placebo or no treatment & 3 & $0.20(0.05$ to 0.74$)$ & $0.29(0.15$ to 0.56$)$ & 0.11 to 0.75 \\
\hline Letrozole & 20 & 1.65 (1.40 to 1.95$)$ & $1.69(1.33$ to 2.14$)$ & 0.83 to 3.43 \\
\hline Metformin & 9 & $1.10(0.62$ to 1.95$)$ & 1.04 (0.74 to 1.46$)$ & 0.49 to 2.21 \\
\hline Clomiphene citrate + metformin & 18 & $1.49(1.18$ to 1.86$)$ & 1.71 (1.28 to 2.27$)$ & 0.82 to 3.53 \\
\hline Tamoxifen & 3 & $0.73(0.30$ to 1.76$)$ & $0.84(0.45$ to 1.58$)$ & 0.33 to 2.13 \\
\hline Follicle stimulating hormone & 2 & 1.57 (1.04 to 2.37$)$ & $1.68(0.87$ to 3.24$)$ & 0.65 to 4.33 \\
\hline Laparoscopic ovarian drilling & 1 & $0.52(0.19$ to 1.44$)$ & $0.52(0.16$ to 1.74$)$ & 0.13 to 2.13 \\
\hline \multicolumn{5}{|l|}{ Placebo or no treatment versus: } \\
\hline Letrozole & NA & NA & $5.81(2.90$ to 11.67$)$ & 2.19 to 15.46 \\
\hline Metformin & 5 & $3.58(2.06$ to 6.21$)$ & $3.59(1.97$ to 6.56$)$ & 1.45 to 8.92 \\
\hline Clomiphene citrate + metformin & NA & NA & 5.88 (2.95 to 11.72$)$ & 2.22 to 15.56 \\
\hline Tamoxifen & NA & NA & 2.91 (1.17 to 7.23$)$ & 0.92 to 9.18 \\
\hline Follicle stimulating hormone & NA & NA & $5.78(2.28$ to 14.66$)$ & 1.80 to 18.55 \\
\hline Laparoscopic ovarian drilling & NA & NA & $1.81(0.46$ to 7.10$)$ & 0.38 to 8.58 \\
\hline \multicolumn{5}{|l|}{ Letrozole versus: } \\
\hline Metformin & 1 & $0.73(0.41$ to 1.32$)$ & $0.62(0.41$ to 0.92$)$ & 0.28 to 1.35 \\
\hline Clomiphene citrate + metformin & NA & NA & $1.01(0.70$ to 1.46$)$ & 0.47 to 2.17 \\
\hline Tamoxifen & 1 & $0.67(0.30$ to 1.47$)$ & $0.50(0.26$ to 0.96$)$ & 0.20 to 1.28 \\
\hline Follicle stimulating hormone & NA & NA & 0.99 (0.49 to 2.00$)$ & 0.37 to 2.65 \\
\hline Laparoscopic ovarian drilling & $\mathrm{NA}$ & NA & 0.31 (0.09 to 1.05$)$ & 0.07 to 1.29 \\
\hline \multicolumn{5}{|l|}{ Metformin versus: } \\
\hline Clomiphene citrate + metformin & 5 & $1.92(0.90$ to 4.06$)$ & $1.64(1.12$ to 2.40$)$ & 0.76 to 3.55 \\
\hline Tamoxifen & NA & NA & $0.81(0.40$ to 1.65$)$ & 0.30 to 2.18 \\
\hline Follicle stimulating hormone & NA & NA & $1.61(0.77$ to 3.36$)$ & 0.59 to 4.41 \\
\hline Laparoscopic ovarian drilling & NA & NA & $0.50(0.14$ to 1.75$)$ & 0.12 to 2.13 \\
\hline \multicolumn{5}{|c|}{ Clomiphene citrate + metformin versus: } \\
\hline Tamoxifen & NA & NA & $0.49(0.25$ to 0.98$)$ & 0.19 to 1.31 \\
\hline Follicle stimulating hormone & NA & NA & 0.98 (0.48 to 2.01$)$ & 0.36 to 2.65 \\
\hline Laparoscopic ovarian drilling & NA & NA & 0.31 (0.09 to 1.05$)$ & 0.07 to 1.29 \\
\hline \multicolumn{5}{|l|}{ Tamoxifen versus: } \\
\hline Follicle stimulating hormone & NA & NA & $1.98(0.80$ to 4.92$)$ & 0.63 to 6.25 \\
\hline Laparoscopic ovarian drilling & NA & NA & 0.62 (0.16 to 2.40$)$ & 0.13 to 2.90 \\
\hline \multicolumn{5}{|c|}{ Follicle stimulating hormone versus: } \\
\hline Laparoscopic ovarian drilling & NA & NA & 0.31 (0.08 to 1.23$)$ & 0.07 to 1.48 \\
\hline
\end{tabular}

laparoscopic ovarian drilling, and placebo or no treatment, respectively (appendix 8). Further details of the analyses on the primary outcome are presented in appendices 9-11.

\section{Secondary outcomes}

Live birth-For the outcome live birth, 23 randomised controlled trials with 4206 women were included in the network meta-analysis. Letrozole resulted in a significantly higher live birth rate compared with clomiphene (odds ratio 1.67, 95\% confidence interval 1.11 to 2.49 ) and metformin led to lower live birth rate than letrozole $(0.54 ; 0.29$ to 0.98$)$. The other comparisons showed no significant differences (appendix 12).

In terms of live birth, letrozole had the highest surface under the cumulative ranking curve value $(81 \%)$, followed by follicle stimulating hormone (74\%), clomiphene and metformin combined (71\%), tamoxifen (48\%), clomiphene (36\%), and metformin $(30 \%)$, while placebo or no treatment $(10 \%)$ had the lowest surface under the cumulative ranking curve value (appendix 13).

Ovulation-For the outcome ovulation per woman randomised, 38 randomised controlled trials were included in the network meta-analysis. Compared with placebo, all interventions except for laparoscopic ovarian drilling led to a significantly higher ovulation rate. These associations remained similar in the network meta-analysis including predictive intervals.

Letrozole (odds ratio 2.00, 95\% confidence interval 1.39 to 2.88 ) led to a higher ovulation rate than clomiphene alone (appendix 14). The combination of clomiphene and metformin was superior to metformin alone $(2.50,1.43$ to 4.36$)$, while metformin was inferior to clomiphene alone (0.57, 0.36 to 0.92$)$. Metformin (0.29, 0.16 to 0.51$)$ was inferior to letrozole.

Follicle stimulating hormone had the highest surface under the cumulative ranking curve value (87\%) in terms of ovulation, followed by letrozole (86\%), clomiphene and metformin combined (70\%), clomiphene $(50 \%)$, tamoxifen (42\%), laparoscopic ovarian drilling (38\%), metformin (24\%), and placebo or no treatment (1\%; appendix 15).

Miscarriage-For the outcome miscarriage, after the exclusion of trials with $0 \%$ or $100 \%$ event rates in all interventions, we included 25 randomised controlled trials in the network meta-analysis. We did not find 


\begin{tabular}{|c|c|c|}
\hline Guidelines/consensus & Condition & First line ovulation induction \\
\hline WHO guideline, $2016^{102}$ & PCOS & Clomiphene or letrozole \\
\hline Australian National Health and Medical Research Council (NHMRC) guideline, 2015 updated $^{104}$ & PCOS & Clomiphene or letrozole \\
\hline $\begin{array}{l}\text { American Association of Clinical Endocrinologists, American College of Endocrinology, and Androgen Excess and } \\
\text { PCOS Society Disease State Clinical Review, } 2015^{103}\end{array}$ & PCOS & Clomiphene or letrozole \\
\hline Italian Society of Endocrinology consensus, $2015^{106}$ & PCOS & Clomiphene \\
\hline European Society of Endocrinology position statement, $2014^{105}$ & PCOS & Clomiphene \\
\hline Endocrine Society, $2013^{6}$ & PCOS & Clomiphene or letrozole \\
\hline National Institute for Health and Care Excellence guideline, $2013^{1}$ & WHO II anovulation & $\begin{array}{l}\text { Clomiphene, metformin, or } \\
\text { clomiphene and metformin combined }\end{array}$ \\
\hline Society of Obstetricians and Gynaecologists of Canada guideline, $2010^{109}$ & PCOS & Clomiphene \\
\hline ESHRE/ASRM consensus, $2008^{107108}$ & PCOS & Clomiphene \\
\hline
\end{tabular}

any significant difference between each comparison in terms of miscarriage per woman randomised or miscarriage per pregnancy in the network metaanalysis (appendices 16 and 17).

Multiple pregnancy-Eighteen trials assessed the outcome multiple pregnancy. When expressed per woman randomised, follicle stimulating hormone led to higher multiple pregnancy rates than metformin (odds ratio 16.17, 95\% confidence interval 1.58 to 165.54). This difference remained significant in network meta-analysis including predictive intervals. Follicle stimulating hormone also led to a higher rate of multiple pregnancy when compared with letrozole (7.22, 1.00 to 51.84). Metformin (0.22, 0.05 to 0.93) led to lower rates of multiple pregnancy compared with clomiphene alone, but these differences were not significant in network meta-analysis including predictive intervals (appendix 18).

Follicle stimulating hormone had the highest surface under the cumulative ranking curve value (90\%), followed by clomiphene $(65 \%)$, tamoxifen (61\%) placebo (47\%), clomiphene and metformin combined (441\%), letrozole (33\%), and metformin (11\%; appendix 19).

Further details of the analyses of the secondary outcomes are presented in appendices 20-32.

\section{Sensitivity analysis results}

When analyses were restricted to studies reporting clinical pregnancy (appendix 33), the results were consistent with the main findings: letrozole and the combination of clomiphene and metformin were superior to clomiphene alone. However, in studies with treatment naive women or studies with low risk of both randomisation and allocation bias, letrozole remained superior to clomiphene (odds ratio 1.80, 95\% confidence interval 1.20 to $2.70 ; 1.97,1.18$ to 3.30 ; respectively), while the difference between clomiphene and metformin combined and clomiphene alone was not significant ( $1.65,0.98$ to $2.80 ; 1.57,0.96$ to 2.57 ; respectively) (appendices 34 and 35).

\section{Discussion}

\section{Summary of key findings}

Our systematic review and network meta-analysis on ovulation induction in infertile women with WHO group II anovulation has three key findings. Firstly, all pharmacological treatments were more effective than placebo or no intervention in terms of achieving ovulation and pregnancy. Secondly, the combination of clomiphene and metformin as well as letrozole on its own were superior to clomiphene in terms of pregnancy, and letrozole was superior to clomiphene in terms of live birth. Lastly, metformin was associated with a lower risk of multiple pregnancy when compared with clomiphene.

\section{Strengths and limitations}

To our knowledge, this is the first application of network meta-analysis in ovulation induction, analysing all the available data and providing a unique opportunity to rank ovulation induction treatments in one pooled analysis. We reported all major reproductive outcomes in infertility trials and performed sensitivity analyses in different dimensions, including study population and study quality. We made these attempts to guarantee the stability of the results. Another strength of our systematic review was the fact that we did not exclude non-English articles or trials published as abstracts only. These trials are often excluded from other meta-analyses, ${ }^{19} 2090$ but in our meta-analysis they contributed $21 \%(12 / 57)$ of studies and $16 \%$ (1321/8082) of women. Therefore, we believe that our analysis included all relevant published randomised controlled trials on ovulation induction in WHO group II anovulation, thus reducing publication bias as much as possible.

Our study also had limitations. Firstly, we only reported reproductive outcomes in our study and were unable to include other relevant outcomes such as side effects that were not reported in many of the primary publications, and the reporting strategies varied from study to study. Metformin, for example, is known to generate gastrointestinal side effects, ${ }^{15}$ but this could not be analysed in our network meta-analysis because it was not systematically reported in all studies. The use of standardised outcomes in studies on ovulation induction would have improved this aspect of our systematic review. ${ }^{272891}$ Additional discussion on the side effects of clomiphene and metformin combined is available in appendices 36-38.

Secondly, we chose pregnancy, defined preferably as clinical pregnancy, as the primary outcome. Although the aim of infertile couples is to have a 
healthy child, the overall sample size of studies reporting on pregnancy was significantly higher than the sample size of studies reporting on live birth. Studies published in the early 2000s or earlier usually followed up participants until pregnancy. To make full use of these data and improve the validity of the transitivity assumption of comparisons among the network, we chose pregnancy as the primary outcome. The conclusions on the effectiveness of a treatment point are often, but not always in women with PCOS, ${ }^{92}$ in the same direction when based either on pregnancy or live birth, while conclusions based on pregnancy as an endpoint are more robust because they have more statistical power. ${ }^{29}$ Ideally, future randomised controlled trials should adhere to the Harbin consensus on outcomes reporting in infertility trials. $^{27} 28$

Thirdly, lifestyle intervention was not analysed in this study. Although lifestyle intervention is recommended in many countries because it leads to higher spontaneous ovulation rates ${ }^{93}$ and natural conceptions rates, ${ }^{94}$ the role of lifestyle intervention in conjunction to drug treatment is controversial in current evidence. According to a recent Dutch study, lifestyle intervention preceding infertility treatment does not lead to better reproductive outcomes within two years in obese infertile women, ${ }^{94}$ whereas lifestyle modification with weight loss before ovulation induction improved ovulation and live birth in PCOS in a US study. ${ }^{95}$

Lastly, WHO group II anovulation is a heterogeneous condition with various clinical manifestations. Women with different genetic backgrounds or metabolic conditions might respond differently to treatment options. The current systematic review only allowed general comparisons among women with WHO group II anovulation. Owing to the various reporting strategies, we chose not to perform subgroup analysis, based on characteristics such as body mass index and hyperandrogenaemia status in this network metaanalysis. Apart from the logistical and governance issues associated with data sharing across different countries, asking the original authors to reanalyse the data can be challenging, in view of the substantial time and effort needed to perform secondary analysis. Additionally, there are several practical difficulties with post hoc selection of cut-off values for continuous variables like body mass index. If the distribution of participants according to biological cut-off values (body mass index 25 or 30) are not balanced across groups, the results of subgroup analysis using this cut-off value could be misleading. Individual participant data meta-analysis would be able to address this issue and allow a more personalised strategy for ovulation induction care.

\section{Research implications}

Traditionally, the effectiveness of a new treatment option comes from comparisons with placebo or current standard care. To date, no trials have compared letrozole with placebo in treatment naive women. The current network meta-analysis, however, provides insight in this comparison from indirect comparisons, and suggests that trials comparing letrozole with placebo are unnecessary and in our opinion even unethical. Evidence on a head-to-head comparison between letrozole and the combination of clomiphene and metformin is lacking. Therefore, new trials comparing these two interventions are needed. Future trials should also compare new treatment options or combinations with one of these two strategies to enrich the evidence on first line management of WHO group II anovulation.

Current evidence showed similar miscarriage rates in women with metformin compared with women with other ovulation induction interventions during the periconceptional period. Future studies on metformin use during pregnancy in women with WHO group II anovulation, including PCOS, can be beneficial.

Individual participant data meta-analysis on this topic is a necessary next step to find target populations for different ovulation induction interventions and therefore to provide evidence for personally targeted infertility care.

\section{Clinical implications and conclusion}

In women with WHO group II anovulation including anovulatory PCOS, expectant management is not recommended, because pharmacological ovulation induction significantly improves pregnancy rate (odds ratios 2.43-6.11) compared with placebo no treatment in the present study.

Letrozole can be recommended as first line treatment due to its higher ovulation, pregnancy, and live birth rate as well as lower multiple pregnancy rate, although the reluctance to adapt such new therapy is common in clinical practice. ${ }^{96}$ The superiority of letrozole over clomiphene was stable in all sensitivity analyses including modifying the criteria of population (treatment naive), reporting strategies (reporting clinical pregnancy) and quality of included studies (low risk of randomisation and allocation bias). Miscarriage is often discussed in the literature especially in women with PCOS, and data in relation to this are controversial. ${ }^{97}$ In our study, there were no significant differences in miscarriage rates in different comparisons; therefore, the superiority of letrozole over clomiphene in terms of live birth does not seem to be related to a decreased miscarriage rate.

Clomiphene and metformin combined can also be recommended as first line treatment, despite the lack of evidence to improve live birth rates and the instability in sensitivity analyses. ${ }^{29}$ Of 18 studies comparing clomiphene and metformin combined with clomiphene or metformin alone, only seven reported live birth. The reduced sample size in the analysis of live birth affected statistical power for this comparison, and could explain the lack of a significant difference between clomiphene and metformin combined and clomiphene alone. The potential higher chances of side effects should also be taken into account in decision making.

Clomiphene alone was not competitive in the network, in terms of effectiveness (pregnancy, live birth, and ovulation) or safety (multiple pregnancy). Gonadotropins, though an effective treatment option, 
had the greatest probability of leading to multiple pregnancy. It is therefore not recommended to use gonadotropins as the first line treatment in treatment naive women with WHO group II anovulation. Further discussions on quality of evidence and interpretation of data is presented in appendix 36 .

Despite the promising results shown in this study, neither letrozole nor metformin are approved for the treatment of anovulation in many countries and continue to be used off-label. ${ }^{9899}$ The use of letrozole for ovulation induction is explicitly prohibited in many other countries ${ }^{100} 101$ (eg, Denmark), except in approved clinical trials. Some guidelines ${ }^{6}{ }^{102-104}$ have recommended clomiphene citrate or letrozole as first line treatment, whereas letrozole has not been included in the scope of other guidelines, ${ }^{1}{ }^{105-109}$ including the National Institute for Health and Care Excellence guidelines in the UK (table 2). ${ }^{1}$ Safety concerns about letrozole use in infertility were raised in a study presented at the American Society for Reproductive Medicine's 2005 annual meeting, which showed a higher risk of locomotor malformations and cardiac anomalies in newborns. ${ }^{110}$ However, this study was criticised on account of its methodological limitations, including small sample size of the letrozole group and inappropriate choice of control group. ${ }^{111}$ This study has not been subsequently published as a peer reviewed paper. According to current evidence (appendix 39), letrozole use in infertility, including PCOS and unexplained infertility, does not increase the risk of congenital anomalies in newborns. ${ }^{49657678111-116}$ These results need to be confirmed by future studies. Moreover, there is an urgent need for long term follow-up data among the offspring of these interventions to confirm the safety of these interventions and help subsequent guideline development.

Laparoscopic ovarian drilling was usually undertaken in clomiphene resistant women, and only one small randomised controlled trial on treatment naive women with PCOS could be included in this network meta-analysis. According to current evidence, including data on long term follow-up, laparoscopic ovarian drilling is recommended as an effective and economic second line treatment for ovulation induction in women with clomiphene resistant PCOS. ${ }^{117-122}$

In conclusion, in women with WHO group II anovulation, both letrozole and the combination of clomiphene and metformin are superior to clomiphene alone in terms of pregnancy. Letrozole is the only treatment showing a significantly higher rate of live birth when compared with clomiphene alone.

\section{AUTHOR AFFILIATIONS}

${ }^{1}$ Robinson Research Institute, Discipline of Obstetrics and Gynaecology, School of Medicine, University of Adelaide, North Adelaide, Australia

${ }^{2}$ Reproductive Medicine Centre, Tongji Hospital, Tongji Medical College, Huazhong University of Science and Technology, Wuhan, China

${ }^{3}$ Centre for Reproductive Medicine, Department of Obstetrics and Gynaecology, Academic Medical Centre, University of Amsterdam, Amsterdam, Netherlands
${ }^{4}$ Department of Obstetrics and Gynaecology, University of Auckland Auckland, New Zealand

${ }^{5}$ School of Women's and Children's Health, University of New South Wales, Sydney, Australia

${ }^{6}$ Department of Obstetrics and Gynaecology, University of Hong Kong, Hong Kong, China

'Department of Obstetrics and Gynecology, Penn State College of Medicine, Hershey, USA

${ }^{8}$ Institute of Applied Health Sciences, University of Aberdeen, Aberdeen, UK

${ }^{9}$ FertilitySA, Adelaide, Australia

${ }^{10} \mathrm{NHMRC}$ (National Health and Medical Research Council) Centre for Research Excellence in Polycystic Ovary Syndrome, Adelaide, Australia

${ }^{11}$ South Australian Health and Medical Research Institute, Adelaide, Australia

We thank Michael Draper (Barr Smith Library, University of Adelaide) for reviewing the search strategies; Mohammad H Zafarmand (University of Amsterdam) for assisting with article translation; all authors of the literature included in this review who responded to requests for additional information on methodology and inclusion criteria; and Susan Seenan (Fertility Network UK), Sasha Ottey (PCOS Challenge), Barbara Collura (RESOLVE), and Sandra Dill (Access Australia's National Infertility Network) for dissemination of the research results.

Contributors: RW, MvW, NPJ, MFC, HZ, RJN, and BWJM contributed to the study conception and design. RW, BVK, and BWIM collected the data. RW and BWJM analysed the data. MvW provided technical support. RW, BVK, MvW, MFC, EHYN, RSL, SB, and BWJM interpreted the work. RW, BVK, and BWJM drafted the manuscript. MvW, NPJ, MFC, HZ, EHYN, RSL, SB, and RJN critically revised the manuscript for important intellectual content. All authors commented on the drafts and approved the final draft. RW and BWJM are the guarantors.

Funding: The work was supported by an Australian government research training programme scholarship (held by RW) and the Australian National Health and Medical Research Council funded Centre for Research Excellence in Polycystic Ovary Syndrome (APP1078444).

Competing interests: All authors have completed the ICMJE uniform disclosure form at www.icmje.org/coi_disclosure.pdf and declare: support from the Australian government research training programme and the Australian National Health and Medical Research Council funded Centre for Research Excellence in Polycystic Ovary Syndrome for the submitted work; NPJ declares having received conference expenses from Bayer Pharma, Merck-Serono, and MSD, research funding from AbbVie, and is a consultant to Vifor Pharma and Guerbet; RSL reports consulting fees from Euroscreen, Kindex, Bayer, and Millendo Pharmaceuticals, and research funding from Ferring, but none of the treatments analysed in the paper conflicted with his consulting or research funding; all other authors declare no financial relationships with any organisations that might have an interest in the submitted work in the previous three years, and no other relationships or activities that could appear to have influenced the submitted work. Ethical approval: Not required.

Data sharing: No additional data available.

The lead author affirms that the manuscript is an honest, accurate, and transparent account of the study being reported; that no important aspects of the study have been omitted; and that any discrepancies from the study as planned (and, if relevant, registered) have been explained.

This is an Open Access article distributed in accordance with the Creative Commons Attribution Non Commercial (CC BY-NC 3.0) license, which permits others to distribute, remix, adapt, build upon this work non-commercially, and license their derivative works on different terms, provided the original work is properly cited and the use is non-commercial. See: http://creativecommons.org/licenses/ by-nc/3.0/.

1 National Institute for Health and Care Excellence. Fertility: assessment and treatment for people with fertility problems. NICE guidance. 2013

2 ESHRE Capri Workshop Group. Health and fertility in World Health Organization group 2 anovulatory women. Hum Reprod Update 2012;18:586-99. doi:10.1093/humupd/dms019

3 Stein IF, Leventhal ML. Amenorrhea associated with bilateral polycystic ovaries. Am J Obstet Gynecol 1935;29:181-91. doi:10.1016/S0002-9378(15)30642-6. 
4 Rotterdam ESHRE ASRM-Sponsored PCOS Consensus Workshop Group. Revised 2003 consensus on diagnostic criteria and long-term health risks related to polycystic ovary syndrome. Fertil Steril 2004;81:19-25. doi:10.1016/j.fertnstert.2003.10.004.

5 Rotterdam ESHRE/ASRM-Sponsored PCOS consensus workshop group. Revised 2003 consensus on diagnostic criteria and long-term health risks related to polycystic ovary syndrome (PCOS). Hum Reprod 2004;19:41-7. doi:10.1093/humrep/deh098

6 Legro RS, Arslanian SA, Ehrmann DAEndocrine Society. Diagnosis and treatment of polycystic ovary syndrome: an Endocrine Society clinical practice guideline. J Clin Endocrinol Metab 2013;98:4565-92. doi:10.1210/jc.2013-2350

7 Sirmans SM, Pate KA. Epidemiology, diagnosis, and management of polycystic ovary syndrome. Clin Epidemiol 2013;6:1-13. doi:10.2147/CLEP.S37559

8 Boomsma CM, Eijkemans MJ, Hughes EG, Visser GH, Fauser BC, Macklon NS. A meta-analysis of pregnancy outcomes in women with polycystic ovary syndrome. Hum Reprod Update 2006;12:673-83. doi:10.1093/humupd/dml036

9 Amsterdam ESHRE/ASRM-Sponsored 3rd PCOS Consensus Workshop Group. Consensus on women's health aspects of polycystic ovary syndrome (PCOS). Hum Reprod 2012;27:14-24. doi:10.1093/ humrep/der396

10 Fauser BC, Tarlatzis BC, Rebar RW. Consensus on women's health aspects of polycystic ovary syndrome (PCOS): the Amsterdam ESHRE/ ASRM-Sponsored 3rd PCOS Consensus Workshop Group. Fertil Steril 2012;97:28-38.e25

11 Hart R, Norman RJ. The longer-term health outcomes for children born as a result of IVF treatment: part I-general health outcomes. Hum Reprod Update 2013;19:232-43. doi:10.1093/humupd/dms062

12 Hansen M, Kurinczuk JJ, Milne E, de Klerk N, Bower C. Assisted reproductive technology and birth defects: a systematic review and meta-analysis. Hum Reprod Update 2013;19:330-53. doi:10.1093/ humupd/dmt006

13 Pinborg A, Wennerholm UB, Romundstad LB. Why do singletons conceived after assisted reproduction technology have adverse perinatal outcome? Systematic review and meta-analysis. Hum Reprod Update 2013;19:87-104. doi:10.1093/humupd/dms044

14 Pandey S, Shetty A, Hamilton M, Bhattacharya S, Maheshwari A. Obstetric and perinatal outcomes in singleton pregnancies resulting from IVF/ICSI: a systematic review and meta-analysis. Hum Reprod Update 2012;18:485-503. doi:10.1093/humupd/dms018

15 Tang T, Lord JM, Norman RJ, Yasmin E, Balen AH. Insulin-sensitising drugs (metformin, rosiglitazone, pioglitazone, D-chiro-inositol) for women with polycystic ovary syndrome, oligo amenorrhoea and subfertility. Cochrane Database Syst Rev 2012;5:CD003053.

16 Franik S, Kremer JA, Nelen WL, Farquhar C. Aromatase inhibitors for subfertile women with polycystic ovary syndrome. Cochrane Database Syst Rev 2014;2:CD010287.

17 Brown J, Farquhar C, Beck J, Boothroyd C, Hughes E. Clomiphene and anti-oestrogens for ovulation induction in PCOS. Cochrane Database Syst Rev 2009; (4):CD002249.

18 Moll E, van der Veen F, van Wely M. The role of metformin in polycystic ovary syndrome: a systematic review. Hum Reprod Update 2007;13:527-37. doi:10.1093/humupd/dmm026

19 Misso ML, Wong JL, Teede HJ. Aromatase inhibitors for PCOS: a systematic review and meta-analysis. Hum Reprod Update 2012;18:301-12. doi:10.1093/humupd/dms003

20 Misso ML, Costello MF, Garrubba M. Metformin versus clomiphene citrate for infertility in non-obese women with polycystic ovary syndrome: a systematic review and meta-analysis. Hum Reprod Update 2013;19:2-11. doi:10.1093/humupd/dms036

21 Mills EJ, Thorlund K, loannidis JP. Demystifying trial networks and network meta-analysis. BMJ 2013;346:f2914. doi:10.1136/bmj. f2914

22 Song F, Loke YK, Walsh T, Glenny AM, Eastwood AJ, Altman DG. Methodological problems in the use of indirect comparisons for evaluating healthcare interventions: survey of published systematic reviews. BMJ 2009;338:b1147. doi:10.1136/bmj.b1147

$23 \mathrm{Lu} \mathrm{G}$, Ades AE. Combination of direct and indirect evidence in mixed treatment comparisons. Stat Med 2004;23:3105-24. doi:10.1002/ sim. 1875

24 Jansen JP, Fleurence R, Devine B. Interpreting indirect treatment comparisons and network meta-analysis for health-care decision making: report of the ISPOR Task Force on Indirect Treatment Comparisons Good Research Practices: part 1. Value Health 2011;14:417-28.

25 Salanti G. Indirect and mixed-treatment comparison, network, or multiple-treatments meta-analysis: many names, many benefits, many concerns for the next generation evidence synthesis tool. Res Synth Methods 2012;3:80-97. doi:10.1002/jrsm.1037

26 Hutton B, Salanti G, Caldwell DM. The PRISMA extension statement for reporting of systematic reviews incorporating network metaanalyses of health care interventions: checklist and explanations. Ann Intern Med 2015;162:777-84. doi:10.7326/M14-2385
27 Harbin Consensus Conference Workshop Group. Improving the Reporting of Clinical Trials of Infertility Treatments (IMPRINT): modifying the CONSORT statement. Fertil Steril 2014;102:952-959.e15.

28 Harbin Consensus Conference Workshop Group, Conference C, Legro RS, Wu X, Scientific C, Barnhart KT, et al. Improving the reporting of clinical trials of infertility treatments (IMPRINT): modifying the CONSORT statement dagger double dagger. Human Reprod 2014;29:2075-82

29 Clarke JF, van Rumste MM, Farquhar CM, Johnson NP, Mol BW, Herbison P. Measuring outcomes in fertility trials: can we rely on clinical pregnancy rates?Fertil Steril 2010;94:1647-51. doi:10.1016/j.fertnstert.2009.11.018

30 Cochrane Handbook for Systematic Reviews of InterventionsCochrane Collaboration. 2011. http://handbook.cochrane.org/.

31 Chaimani A, Higgins JP, Mavridis D, Spyridonos P, Salanti G. Graphical tools for network meta-analysis in STATA. PLoS One 2013;8:e76654. doi:10.1371/journal.pone.0076654

32 Chaimani A, Salanti G. Visualizing assumptions and results in network meta-analysis: The network graphs package. Stata / 2015;15:905-50.

33 Salanti G, Ades AE, loannidis JP. Graphical methods and numerical summaries for presenting results from multiple-treatment metaanalysis: an overview and tutorial. J Clin Epidemiol 2011;64:163-71. doi:10.1016/j.jclinepi.2010.03.016

34 Abuelghar WM, Elkady OS, Khamees AA. Clomiphene citrate alone, in combination with metformin or in combination with pioglitazone as first line therapy in induction of ovulation in infertile women with polycystic ovary syndrome, a randomized controlled trial. Middle East Fertil Soc J 2013;18:135-41doi:10.1016/j.mefs.2013.05.002.

35 Amer S, Fakis A, Smith J, Shaw R, Mahran A. Double blind cross-over randomized controlled trial comparing letrozole versus clomiphene citrate for ovulation induction in women with polycystic ovarian syndrome. Hum Reprod 2015;30:i96.

36 Amer SA, Li TC, Metwally M, Emarh M, Ledger WL. Randomized controlled trial comparing laparoscopic ovarian diathermy with clomiphene citrate as a first-line method of ovulation induction in women with polycystic ovary syndrome. Hum Reprod 2009;24:21925. doi:10.1093/humrep/den325

37 Atay V, Cam C, Muhcu M, Cam M, Karateke A. Comparison of letrozole and clomiphene citrate in women with polycystic ovaries undergoing ovarian stimulation. J Int Med Res 2006;34:73-6. doi:10.1177/147323000603400109

38 Ayaz A, Alwan Y, Farooq MU. Metformin-clomiphene citrate vs. clomiphene citrate alone: Polycystic ovarian syndrome. / Hum Reprod Sci 2013;6:15-8. doi:10.4103/0974-1208.112372

39 Aygen EM, Güzel Z, Özgün T, Atakul T, Şahin Y. The use of letrozole for ovulation induction in infertile women with polycystic ovarian syndrome. Erciyes Tip Dergisi 2007;29:195-200.

40 Reference removed from version 2 of this systematic review.

41 Reference removed from version 2 of this systematic review.

42 Basirat Z, Kashifard M, Amiri MG. Enhanced ovarian folliclular development by metformin does not correlate with pregnancy rate: a randomized trial. Int J Fertil Steril 2012;6:31-6.

43 Bayar U, Basaran M, Kiran S, Coskun A, Gezer S. Use of an aromatase inhibitor in patients with polycystic ovary syndrome: a prospective randomized trial. Fertil Steril 2006;86:1447-51. doi:10.1016/j. fertnstert.2006.04.026

44 Beigi A. Randomized trial comparing clomiphene citrate and metformin as the first-line treatment for ovulation induction in polycystic ovary syndrome. Hum Reprod 2006;21(Suppl):i129.

45 Boostanfar R, Jain JK, Mishell DRJr, Paulson RJ. A prospective randomized trial comparing clomiphene citrate with tamoxifen citrate for ovulation induction. Fertil Steril 2001;75:1024-6. doi:10.1016/ S0015-0282(01)01749-6

46 Boudhrâa K, Jellouli MA, Amri M, Farhat M, Torkhani F, Gara MF. [Indication of metformin in the management of hormonal dysfunction secondary to polycystic ovarian syndrome: prospective comparative study of 63 cases]. Tunis Med 2010;88:335-40.

47 Cudmore DW, Tupper WR. Induction of ovulation with clomiphene citrate. A double-blind study. Fertil Steril 1966;17:363-73. doi:10.1016/S0015-0282(16)35947-7

48 Dasari P, Pranahita G. The efficacy of metformin and clomiphene citrate combination compared with clomiphene citrate alone for ovulation induction in infertile patients with PCOS. J Hum Reprod Sci 2009;2:18-22. doi:10.4103/0974-1208.51337

49 Dehbashi S, Dehbashi S, Kazerooni T. Comparison of the effects of letrozole and clomiphene citrate on ovulation and pregnancy rate in patients with polycystic ovary syndrome. Iran J Med Sci 2009;34:23-8.

50 El-Biely MM, Habba M. The use of metformin to augment the induction of ovulation in obese infertile patients with polycystic ovary syndrome. Middle East Fertil Soc / 2001;6:43-9.

51 Fleming R, Hopkinson ZE, Wallace AM, Greer IA, Sattar N. Ovarian function and metabolic factors in women with oligomenorrhea treated with metformin in a randomized double blind placebocontrolled trial. J Clin Endocrinol Metab 2002;87:569-74. doi:10.1210/jcem.87.2.8261 
52 Garcia CR, Freeman EW, Rickels K. Behavioral and emotional factors and treatment responses in a study of anovulatory infertile women. Fertil Steril 1985;44:478-83. doi:10.1016/S00150282(16)48915-6

53 Homburg R, Hendriks ML, König TE. Clomifene citrate or low-dose FSH for the first-line treatment of infertile women with anovulation associated with polycystic ovary syndrome: a prospective randomized multinational study. Hum Reprod 2012;27:468-73. doi:10.1093/humrep/der401

54 Jahan S. Comparative study of efficacy among metformin, clomiphene citrate and aromatase inhibitor (letrozole) as the first-line medication for ovulation induction, achievement of pregnancy and live birth in Asian women with polycystic ovarian syndrome: A prospective trial. Int J Gynaecol Obstet 2015;131:E503.

55 Johnson JEJr, Cohen MR, Goldfarb AF. The efficacy of clomiphene citrate for induction of ovulation. A controlled study. Int Fertil 1966;11:265-70.

56 Johnson NP, Stewart AW, Falkiner JREACT-NZ (REproduction And Collaborative Trials in New Zealand), a multi-centre fertility trials group. PCOSMIC: a multi-centre randomized trial in women with PolyCystic Ovary Syndrome evaluating Metformin for Infertility with Clomiphene. Hum Reprod 2010;25:1675-83. doi:10.1093/humrep/deq100

57 Kar S. Clomiphene citrate or letrozole as first-line ovulation induction drug in infertile PCOS women: A prospective randomized trial. J Hum Reprod Sci 2012;5:262-5. doi:10.4103/0974-1208.106338

58 Kar S, Sanchita S. Clomiphene citrate, metformin or a combination of both as the first line ovulation induction drug for Asian Indian women with polycystic ovarian syndrome: A randomized controlled trial. / Hum Reprod Sci 2015;8:197-201. doi:10.4103/0974-1208.170373

59 Karimzadeh MA, Eftekhar M, Taheripanah R, Tayebi N, Sakhavat L, Zare F. The effect of administration of metformin on lipid profile changes and insulin resistance in patients with polycystic ovary syndrome. Middle East Fertil Soc 1 2007:12:174-8.

60 Karimzadeh MA, Javedani M. An assessment of lifestyle modification versus medical treatment with clomiphene citrate, metformin, and clomiphene citrate-metformin in patients with polycystic ovary syndrome. Fertil Steril 2010;94:216-20. doi:10.1016/j. fertnstert.2009.02.078

61 Keikha F. Shahraki Mojahed B. Induction ovulation in polycystic ovary patient with clomiphene citrate and letrozole. Iran J Reprod Med 2011;9:46.

62 Khorram O, Helliwell JP, Katz S, Bonpane CM, Jaramillo L. Two weeks of metformin improves clomiphene citrate-induced ovulation and metabolic profiles in women with polycystic ovary syndrome. Fertil Steril 2006;85:1448-51. doi:10.1016/j.fertnstert.2005.10.042

63 Leanza V, Coco L, Grasso F, Leanza G, Zarbo G, Palumbo M. Ovulation induction with clomiphene citrate and metformin in women with polycystic ovary syndrome. Minerva Ginecol 2014;66:299-301.

64 Legro RS, Barnhart HX, Schlaff WDCooperative Multicenter Reproductive Medicine Network. Clomiphene, metformin, or both for infertility in the polycystic ovary syndrome. N Engl Med 2007;356:551-66. doi:10.1056/NEJMoa063971

65 Legro RS, Brzyski RG, Diamond MPNICHD Reproductive Medicine Network. Letrozole versus clomiphene for infertility in the polycystic ovary syndrome. N Engl J Med 2014;371:119-29. doi:10.1056/ NEJMoa1313517

66 Liu C, Feng G, Wang Q, Xiao L. Huang W. Comparison of ovulation induction protocol for women with polycystic ovarian syndrome: $A$ prospective randomized trial. Int J Gynaecol Obstet 2015;131:E231-2.

67 López E, Gunby J, Daya S, Parrilla JJ, Abad L, Balasch J. Ovulation induction in women with polycystic ovary syndrome: randomized trial of clomiphene citrate versus low-dose recombinant FSH as first line therapy. Reprod Biomed Online 2004;9:382-90. doi:10.1016/ S1472-6483(10)61273-4

68 Lord J, Thomas R, Fox B, Acharya U, Wilkin T. The effect of metformin on fat distribution and the metabolic syndrome in women with polycystic ovary syndrome--a randomised, double-blind, placebocontrolled trial. BJOG 2006;113:817-24. doi:10.1111/j.14710528.2006.00966.x

69 Lorzadeh N, Kazemirad S, Mohammadi Z. Comparison of effects letrozole and clomiphene citrate for ovulation induction in women with polycystic ovary syndrome. Iran J Obstet Gynecol Infertil 2011;14:13-9.

70 Maged AM, Elsawah $\mathrm{H}$, Abdelhafez A, Bakry A, Mostafa WAl. The adjuvant effect of metformin and $\mathrm{N}$-acetylcysteine to clomiphene citrate in induction of ovulation in patients with polycystic ovary syndrome. Gynecol Endocrinol 2015;31:635-8.doi:10.3109/09513 590.2015.1037269

71 Mobusher I. Comparison of the efficacy of letrozole and clomiphene citrate for ovulation induction in infertile women with polycystic ovary syndrome. Pak / Med Health Sci 2014:8:905-8.

72 Moll E, Bossuyt PM, Korevaar JC, Lambalk CB, van der Veen F. Effect of clomifene citrate plus metformin and clomifene citrate plus placebo on induction of ovulation in women with newly diagnosed polycystic ovary syndrome: randomised double blind clinical trial. BMJ 2006;332:1485. doi:10.1136/bmj.38867.631551.55
73 Nazik H, Kumtepe Y. Comparison of efficacy of letrozole and clomiphene citrate in ovulation induction for women with polycystic ovarian syndrome. Health Med 2012;6:879-83.

74 Palomba S, Orio FJr, Falbo A. Prospective parallel randomized, doubleblind, double-dummy controlled clinical trial comparing clomiphene citrate and metformin as the first-line treatment for ovulation induction in nonobese anovulatory women with polycystic ovary syndrome. J Clin Endocrinol Metab 2005;90:4068-74. doi:10.1210/jc.2005-0110

75 Reference removed from version 2 of this systematic review.

76 Banerjee Ray P, Ray A, Chakraborti PS. Comparison of efficacy of letrozole and clomiphene citrate in ovulation induction in Indian women with polycystic ovarian syndrome. Arch Gynecol Obstet 2012:285:873-7. doi:10.1007/s00404-011-2091-7

77 Robinson R, Swezey M, Propst A, Bates G. Metformin added to clomiphene citrate does not improve pregnancy rates in hyperandrogenic, chronic anovulatory women: A randomized trial[abstract no: P.]. Fertil Steril 2003;80(Suppl 3):S273-4. doi:10.1016/S0015-0282(03)01695-9.

78 Roy KK, Baruah J, Singla S. A prospective randomized trial comparing the efficacy of Letrozole and Clomiphene citrate in induction of ovulation in polycystic ovarian syndrome. I Hum Reprod Sci 2012;5:20-5. doi:10.4103/0974-1208.97789

79 Sahin Y, Yirmibeș U, Keleștimur F, Aygen E. The effects of metformin on insulin resistance, clomiphene-induced ovulation and pregnancy rates in women with polycystic ovary syndrome. Eur J Obstet Gynecol Reprod Biol 2004:113:214-20 doi:10.1016/j.ejogrb.2003.09.036

80 Santonocito V, Rapisarda V, Abruzzo SRM, Pollicino R, Coco L, Zarbo G. Comparison between clomiphene citrate and metformin for induction of ovulatory cycles in infertile nonobese women with polycystic ovary syndrome. Giornale Italiano di Ostetricia e Ginecologia 2009;31:455-60

81 Selim MF, Borg TF. Letrozole and clomiphene citrate effect on endometrial and subendometrial vascularity in treating infertility in women with polycystic ovary syndrome. 2012;28:405-10.

82 Seyedoshohadaei F, Zandvakily F, Shahgeibi S. Comparison of the effectiveness of clomiphene citrate, tamoxifen and letrozole in ovulation induction in infertility due to isolated unovulation. Iran Reprod Med 2012;10:531-6.

83 Sharief M, Nafee NR. Comparison of letrazole and clomiphene citrate in women with polycystic ovaries undergoing ovarian stimulation. I Pak Med Assoc 2015;65:1149-52

84 Sheikh-El-Arab Elsedeek M, Elmaghraby HAH. Predictors and characteristics of letrozole induced ovulation in comparison with clomiphene induced ovulation in anovulatory PCOS women. Middle East Fertil Soc J 2011;16:125-30doi:10.1016/j.mefs.2010.11.004

85 Tang T, Glanville J, Hayden Cl, White D, Barth JH, Balen AH. Combined lifestyle modification and metformin in obese patients with polycystic ovary syndrome. A randomized, placebo-controlled, double-blind multicentre study. Hum Reprod 2006;21:80-9. doi:10.1093/ humrep/dei311

86 Vegetti W, Riccaboni A, Columbo MRandomized study of induction of ovulation by two different molecules with antioestrogenic effects, in patients with chronic anovulation disorders. 1999;72(3 Suppl 1):S234-5.

87 Williams CD, Pastore LM, Shelly WB, Bailey AP, Baras DC, Bateman $B G$. A randomized, placebo-controlled study of the influence of instant-release metformin on response to clomiphene citrate and time to conception in polycystic ovary syndrome. Fertil Steril 2009;92:S105doi:10.1016/j.fertnstert.2009.07.1076.

88 Zain MM, Jamaluddin R, Ibrahim A, Norman RJ. Comparison of clomiphene citrate, metformin, or the combination of both for first-line ovulation induction, achievement of pregnancy, and live birth in Asian women with polycystic ovary syndrome: a randomized controlled trial. Fertil Steril 2009;91:514-21. doi:10.1016/j. fertnstert.2007.12.002

89 Zeinalzadeh M, Basirat Z, Esmailpour M. Efficacy of letrozole in ovulation induction compared to that of clomiphene citrate in patients with polycystic ovarian syndrome. J Reprod Med 2010;55:36-40.

90 Roque M, Tostes AC, Valle M, Sampaio M, Geber S. Letrozole versus clomiphene citrate in polycystic ovary syndrome: systematic review and meta-analysis. Gynecol Endocrinol 2015;31:917-21.

91 Khan K. The CROWN Initiative: journal editors invite researchers to develop core outcomes in women's health. BJOG 2014;121:1181-2. doi:10.1111/1471-0528.12929

92 Chen ZJ, Shi Y, Sun Y. Fresh versus frozen embryos for infertility in the polycystic ovary syndrome. N Engl / Med 2016;375:523-33. doi:10.1056/NEJMoa1513873

93 Legro RS, Dodson WC, Kris-Etherton PM. Randomized controlled trial of preconception interventions in infertile women with polycystic ovary syndrome. J Clin Endocrinol Metab 2015;100:4048-58. doi:10.1210/jc.2015-2778

94 Mutsaerts MA, van Oers AM, Groen H. Randomized trial of a lifestyle program in obese infertile women. N Engl J Med 2016;374:1942-53. doi:10.1056/NEJMoa1505297 
95 Legro RS, Dodson WC, Kunselman AR. Benefit of delayed fertility therapy with preconception weight loss over immediate therapy in obese women with PCOS. / Clin Endocrinol Metab 2016;101:265866. doi:10.1210/jc.2016-1659

96 McCartney CR, Marshall JC. Clinical practice. Polycystic ovary syndrome. N Engl I Med 2016;375:54-64. doi:10.1056/NEJMcp1514916

97 Palomba S, de Wilde MA, Falbo A, Koster MP, La Sala GB, Fauser BC Pregnancy complications in women with polycystic ovary syndrome. Hum Reprod Update 2015;21:575-92. doi:10.1093/humupd/dmv029

98 Vitek W, Alur S, Hoeger KM. Off-label drug use in the treatment of polycystic ovary syndrome. Fertil Steril 2015;103:605-11. doi:10.1016/j.fertnstert.2015.01.019

99 Usadi RS, Merriam KS. On-label and off-label drug use in the treatment of female infertility. Fertil Steril 2015;103:583-94. doi:10.1016/j.fertnstert.2015.01.011

100 Birch Petersen K, Pedersen NG, Pedersen AT, Lauritsen MP, la Cour Freiesleben N. Mono-ovulation in women with polycystic ovary syndrome: a clinical review on ovulation induction. Reprod Biomed Online 2016;32:563-83. doi:10.1016/j.rbmo.2016.03.006

101 Palomba S. Aromatase inhibitors for ovulation induction. J Clin Endocrinol Metab 2015;100:1742-7. doi:10.1210/jc.2014-4235

102 Balen AH, Morley LC, Misso M. The management of anovulatory infertility in women with polycystic ovary syndrome: an analysis of the evidence to support the development of global WHO guidance. Hum Reprod Update 2016;22:687-708. doi:10.1093/humupd/dmw025

103 Goodman NF, Cobin RH, Futterweit W, Glueck IS, Legro RS, Carmina EAmerican Association of Clinical Endocrinologists (AACE)American College of Endocrinology (ACE)Androgen Excess and PCOS Society. American Association of Clinical Endocrinologists, American College of Endocrinology, and Androgen Excess and Pcos Society Disease State Clinical Review: Guide to the Best Practices in the Evaluation and Treatment of Polycystic Ovary Syndrome - Part 2. Endocr Pract 2015:21:1415-26 doi:10.4158/EP15748.DSCPT2

104 National Health and Medical Research Council. Evidence-based guideline for the assessment and management of polycystic ovary syndrome (updated August 2015 - section 7.4 aromatase inhibitors). 2015 https://www.nhmrc.gov.au/_files_nhmrc/publications/ attachments/pcos_guideline_updated_18082015_v3.pdf.

105 Conway G, Dewailly D, Diamanti-Kandarakis EESE PCOS Special Interest Group. The polycystic ovary syndrome: a position statement from the European Society of Endocrinology. Eur J Endocrinol 2014;171:1-29. doi:10.1530/EJE-14-0253

106 Moghetti P, Carmina E, De Leo V. How to manage the reproductive issues of PCOS: a 2015 integrated endocrinological and gynecological consensus statement of the Italian Society of Endocrinology. J Endocrinol Invest 2015;38:1025-37. doi:10.1007/ s40618-015-0274-y

107 Thessaloniki ESHRE/ASRM-Sponsored PCOS Consensus Workshop Group. Consensus on infertility treatment related to polycystic ovary syndrome. Fertil Steril 2008;89:505-22. doi:10.1016/. fertnstert.2007.09.041

108 Thessaloniki ESHRE/ASRM-Sponsored PCOS Consensus Workshop Group. Consensus on infertility treatment related to polycystic ovary syndrome. Hum Reprod 2008;23:462-77. doi:10.1093/humrep/ dem 426

109 Vause TD, Cheung AP, Sierra SSociety of Obstetricians and Gynecologists of Canada. Ovulation induction in polycystic ovary syndrome [correction in: J Obstet Gynaecol Can 2010;32:1027] J Obstet Gynaecol Can 2010:32:495-502. doi:10.1016/S17012163(16)34504-2
110 Biljan MM, Hemmings R, Brassard N. The outcome of 150 babies following the treatment with letrozole or letrozole and gonadotropins. Fertil Steril 2005;84(Suppl 1):S95doi:10.1016/j. fertnstert.2005.07.230

111 Forman R, Gill S, Moretti M, Tulandi T, Koren G, Casper R. Fetal safety of letrozole and clomiphene citrate for ovulation induction. J Obstet Gynaecol Can 2007;29:668-71. doi:10.1016/S17012163(16)32551-8

112 Diamond MP Legro RS, Coutifaris CNICHD Reproductive Medicine Network. Letrozole, gonadotropin, or clomiphene for unexplained infertility. N Engl J Med 2015;373:1230-40. doi:10.1056/ NEJMoa1414827

113 Sharma S, Ghosh S, Singh S. Congenital malformations among babies born following letrozole or clomiphene for infertility treatment. PLoS One 2014;9:e108219. doi:10.1371/journal. pone.0108219

114 Tulandi T, Martin J, Al-Fadhli R. Congenital malformations among 911 newborns conceived after infertility treatment with letrozole or clomiphene citrate. Fertil Steril 2006;85:1761-5. doi:10.1016/j. fertnstert.2006.03.014

115 Tatsumi T, Jwa SC, Kuwahara A, Irahara M, Kubota T, Saito H. No increased risk of major congenital anomalies or adverse pregnancy or neonatal outcomes following letrozole use in assisted reproductive technology. Hum Reprod 2017;32:125-32. doi:10.1093/humrep/ dew280

116 Wu XK, Wang YY, Liu JPReproductive and Developmental Network in Chinese Medicine. Randomized controlled trial of letrozole, berberine or a combination for infertility in the polycystic ovary syndrome. Fertil Steril 2016;106:757-765.e1.

117 Abu Hashim H, Al-Inany H, De Vos M, Tournaye H. Three decades after Gjönnaess's laparoscopic ovarian drilling for treatment of PCOS; what do we know? An evidence-based approach. Arch Gynecol Obstet 2013.288:409-22 doi:10.1007/s00404-013-2808-x

118 Farquhar C, Brown J, Marjoribanks J. Laparoscopic drilling by diathermy or laser for ovulation induction in anovulatory polycystic ovary syndrome. Cochrane Database Syst Rev 2012;6:CD001122.

119 Bayram N, van Wely M, Kaaijk EM, Bossuyt PM, van der Veen F. Using an electrocautery strategy or recombinant follicle stimulating hormone to induce ovulation in polycystic ovary syndrome: randomised controlled trial. BMJ 2004;328:192. doi:10.1136/ bmj.328.7433.192

120 Nahuis MJ, Kose N, Bayram N. Long-term outcomes in women with polycystic ovary syndrome initially randomized to receive laparoscopic electrocautery of the ovaries or ovulation induction with gonadotrophins. Hum Reprod 2011;26:1899-904. doi:10.1093/ humrep/der141

121 Nahuis MJ, Oude Lohuis E, Kose N. Long-term follow-up of laparoscopic electrocautery of the ovaries versus ovulation induction with recombinant FSH in clomiphene citrate-resistant women with polycystic ovary syndrome: an economic evaluation. Hum Reprod 2012;27:3577-82. doi:10.1093/humrep/des336

122 Nahuis MJ, Oude Lohuis EJ, Bayram N. Pregnancy complications and metabolic disease in women with clomiphene citrate-resistant anovulation randomized to receive laparoscopic electrocautery of the ovaries or ovulation induction with gonadotropins: a 10-year follow-up. Fertil Steril 2014;101:270-4. doi:10.1016/j. fertnstert.2013.09.004

\section{Appendices: Supplementary material}

